\title{
An Insight into a Whole School Experience: The Implementation of Teaching Teams to Support Learning and Teaching
}

\author{
By Charmaine Agius Ferrante*
}

This paper presents some of the emerging outcomes from the experiences of a Maltese school that decided to embrace the philosophy of inclusion using a whole school approach based on the social model of disability. This was a qualitative study based on focus groups. A thematic analysis was used within an interpretative approach of hermeneutic phenomenology. Most schools in Malta now include 'inclusive' settings. This entails the use of a class Learning Support Assistant who is assigned to one or more classes where there are one or more children statemented as having learning difficulties. It is the usual practice for most Learning Support Assistants (LSAs) to follow the same child/children exclusively. All too frequently, teachers work separately. The outcome of the teachers' work has little or no effect on and is not affected by the actions of other educators. Teachers do their own work with their class and LSAs do their own work with the disabled student/s in class. The aim of the research was to generally explore the whole experience of one school in including disabled learners. The specific research questions for this part of the study were the following:

1. How can teaching teams reduce the barriers to education for all learners?

2. What practices within this model support or hinder the inclusion and education of disabled learners in a mainstream environment?

Finally, there will be an attempt to expose the idealised notions of the fundamental principle of "schools for all". Social justice, disability, equality and human rights issues that underpin the social model of disability are being responded to within the "Special" Education discourse, creating exclusionary practice and inequalities within education.

Keywords: inclusive education, learning support assistants (LSAs), teaching teams.

\section{Introduction}

The main drive behind this paper is to positively present an account of research practice from an insider perspective on how disabled children and students can be supported in their mainstream classrooms. The biggest barriers to inclusive education can be the adults (Oliver, 1990; Titchkosky, 2003; Goodley, 2010) and the less than appropriate support systems (Lindqvist, Nilholm, Almqvist, \& Westo, 2011). Support does matter and seeking the balance between teacher and Learning Support Assistant (LSA) involvement is key to good educational practice. To effectively research the LSAs' influence on inclusive

\footnotetext{
${ }^{*}$ Senior Lecturer, Northumbria University, UK.
} 
practice, this study explored learning and teaching together with social inclusion. The research arose in the context of emphasis placed on inclusion of disabled children and students in mainstream schools in Malta. In Malta, one of the most remarkable developments has been the Maltese Ministry of Education's incremental phasing-in of an inclusive education policy in 1994. The result is that the majority of disabled children and students receive their education in mainstream schools. The research was carried out for completion of a $\mathrm{PhD}$ (Agius Ferrante, 2012). The researcher was herself situated in the school and the school staff, parents and students were clear that they themselves valued the prospect of the study that would focus on this particular school's inclusive educational journey. From the outset, it is important to characterise this study's understanding of the discourse of disabled children and students within inclusive education. Children and students, whether with physical, learning, sensorial or other impairments, are identified as learners within a community of learners. All the learners are placed in mixed ability mainstream classrooms supported by a teacher and two LSAs; where they are authentically engaged and learn together with the required supports.

The teaching teams attempt to meet the needs of all learners at the onset of instruction by building in supports and scaffolds into their lessons plans. The teaching teams create a culture in which disability is accepted and embraced (Bernacchio \& Mullen, 2007). The predominant finding in this study was the need to coordinate LSA support through the creation of teaching teams. Participants reported that ongoing, and conjoint processes of planning together when working in a team, are not only key to the inclusion of the disabled learner but of all learners and educators.

\section{Literature Review}

\section{Inclusive Education}

The concept of inclusive education is viewed as a process located within the culture, policies and practices of the whole school (Salamanca Statement, UNESCO, 1994). Whilst education is often regarded as a decisive constituent in the development and progress of society, the teaching and learning for disabled children and students in inclusive classrooms in many countries continues to be provided by leaning support assistants (LSAs). The historic evidence that disabled children and students do not receive the same kind of schooling as their nondisabled peers and experience social exclusion is overwhelming and not in dispute (Oliver, 1996). Children learn when they are together, encapsulated in the same experiences, interacting together (Salend, 2008). Despite the benefits, there are several key implications for the disabled children when they learn alongside their non-disabled peers in terms of accessing the learning and teaching in the classroom. Previous research indicates that teachers are hesitant to accept responsibility for disabled students (Pijl, 2010). Inclusive education is not about having a partial view of inclusion, but lies in the search for the processes 
of equity where excellence and choice are turned into positive influences rather than negative essentials of schooling. Inclusion is about education getting it right for all learners.

\section{Learning Support Assistants (LSAs)}

As the title suggests the role is around support, which has proved to be problematic when directed entirely towards the disabled learner without a thought for the teacher, the class as a whole, active learning and teaching participation and independence (Agius Ferrante \& Falzon, 2011; Agius Ferrante, 2012; Blatchford, Russell, \& Webster, 2012). Given the increasing evidence that LSAs are seen to be essential for the implementation of inclusive practice and indeed essential for a disabled learner's daily attendance within the classroom (Webster, Blachford, Bassett, Martin, \& Russell, 2011), it is important to understand this complex and shifting role and the influence of the LSAs on students' learning. LSAs not only assist the teacher in developing the disabled learners' academic abilities; they also enable the student to nurture their social skills and to progress with confidence throughout their school journey.

\section{Teaching Teams}

Whilst the nature of the relationship between teachers and LSAs is constantly changing, it is very much left up to the individual school leaders, and in most schools, to the classroom or subject teachers and the LSA to evolve the relationship between them. The creation of teaching teams in the school studied came about through training and experience. Organisationally, there must be structures to develop new approaches to the role of the LSA and towards the organisation of teaching teams allowing them to collaborate with one another in order to facilitate the learning and teaching of all the learners in their classrooms (Agius Ferrante, 2008). Best practice is associated with the teacher and the LSA working as partners in the classroom (Agius Ferrante, 2012). One of the successes of in-class support is the quality of joint planning of the work between class/subject teacher and the class/subject LSA (Agius Ferrante \& Falzon, 2011). Collaborative teamwork comes about when all members of the team have common goals and a shared understanding (O'brien \& Garner, 2001).

Developing a shared framework helps identify the common denominators that exist among team members who often hold diverse opinions. If a group does not work to clarify a shared framework on an ongoing basis, it will perpetually interfere with their work and they are unlikely to become a real team. Team members are constantly struggling with redefining roles, relationships and responsibilities in order to collaborate more effectively. In schools, the instructional strategies associated with each discipline are among the most significant contributions team members make in the collaborative teamwork process. The incorporation of different perspectives increases the effectiveness of the educational experience for all learners. 


\section{Disabled Learner}

In the light of inclusive education, the core values of disability culture that underline political struggles include an acceptance of human difference, recognition of human interdependence and of the ability to construct complex learning journeys. Early Intervention has been defined as the provision of support to families through a programme used with infants and young children, who have or are at risk of having an impairment or learning disability. Parents are supported by and work together with early interventionists to support their child's development through the use of different activities and experiences. Early Intervention affects the child, the parents and the way in which the family functions. Dunst (2003) mentions the importance of Early Intervention as being empowering - thus utilising capabilities for the development of new competencies.

The proportion of disabled learners attending the school studied was above the national intake. Disabled learners in this study can be identified as learners with particular labels attached to them. All the learners were between the ages of 5 and 16 years old and had attended the school from their first year of primary school. All the learners had received early intervention and had an educational statement for in-class support. Due to the fact that they had a range of impairments (sensorial, physical, intellectual and multiple impairments), they brought different contrasts and emphasis into the fabric of school.

\section{Methodology}

\section{Case Study}

This study employed case-study methods (Yin, 2014). It was a qualitative study based on four focus groups. Using a case study method insured the capacity to explore this school in an in-depth, meaningful way (Luck, Jackson, \& Usher, 2006; Batstone, Waghorn, \& Tobias, 2016). The school was located in the central region of Malta. Grade levels within the school included Grade 1 to form 5. School enrollment was 1042 students of whom 114 had an educational statement. A thematic analysis was used within an interpretative approach of hermeneutic phenomenology, as the aim of the study was to develop a greater understanding of the experiences and perspectives of inclusive practice through the consciousness of the individual (Husserl, 1970). This allowed an exploration of a specific situation through the description and interpretation of a lived experience around inclusive education (Mayoh \& Onwuegbuzie, 2013).

The data from the four focus groups is discussed in relation to the theory of inclusion in order to illuminate the nature of the processes, which led to and supported the development of teaching teams as a model of inclusive education.

\section{Focus Groups}

The aim of the focus groups was to explore how the teacher-LSA teams 
were supporting the learning of a diverse population of students and their implications. Prior to meeting the focus groups and following the analysis of the teacher/LSA questionnaires and the interviews of both the head of the primary and secondary school, I wrote nine questions from the themes developed from data analysis of the interview transcripts and questionnaires. To generate richer data, Barbour (2014) suggests combining interviews and focus groups to elicit information from participants both privately and publicly whilst addressing the most prominent themes previously highlighted by them in the interviews (Hennink, Hutter, \& Bailey, 2011). The four focus group participants worked in and across teaching teams throughout the school. Their participation was on a voluntary basis. Each focus group consisted of key members of the teaching staff that included assistant head teachers and class or subject teachers together with their class or subject LSA, and a critical friend (Bassey, 1995) with whom I had a discussion on the outcomes of the focus group immediately after each session. The critical friend came from an education and disability studies background. All four focus groups were observed in practice by the critical friend and then evaluated and discussed with myself. All focus groups were audio recorded, transcribed verbatim and reviewed by the critical friend confirming the group dynamics and confirming the collaborative practices of the different teaching teams.

\section{Thematic Analysis}

I read and reread all the transcripts and coded them individually, initially using codes from the research questions and key words. I continually reviewed and revised the codes as needed and searched for patterns in the coding that yielded themes. I analysed emerging patterns across the four focus groups. The main thematic categories generated from the four focus groups will be discussed in the results section.

\section{Results}

\section{Focus Group Findings}

The debate in the focus groups centered on the following extremely interesting issues and debates that came from the research questions about the creation of teaching teams and the implementation of teamwork. The main themes elicited were diversity in the classroom, teaching teams, pedagogy and positive practice, and staff development and training. The themes and subthemes are presented in Table 1 below. 
Table 1. Themes Derived from Focus Groups

\begin{tabular}{|c|c|}
\hline Themes & Sub themes \\
\hline $\begin{array}{l}\text { 1. Diversity in the } \\
\text { classroom }\end{array}$ & $\begin{array}{ll}\text { 1.1 } & \text { Attitude } \\
\text { 1.2 } & \text { Mixed ability } \\
\text { 1.3 } & \text { Planning } \\
\text { 1.4 } & \text { Behaviour } \\
\text { 1.5 } & \text { Inclusive classroom strategies } \\
\text { 1.6 } & \text { Resources } \\
\end{array}$ \\
\hline 2. Teaching Teams & $\begin{array}{l}\text { 2.1 Working together } \\
\text { 2.2 Indicators of effective staff collaboration } \\
\text { 2.3 Contact time between teacher and LSA } \\
2.4 \text { Meetings } \\
\end{array}$ \\
\hline 3. Support Structures & $\begin{array}{ll}\text { 3.1 } & \text { LSA support } \\
\text { 3.2 } & \text { In class support } \\
3.3 & \text { Accommodations, Differentiation } \\
\text { 3.4 } & \text { Peer support }\end{array}$ \\
\hline $\begin{array}{l}\text { 4. Pedagogy and Positive } \\
\text { Practice }\end{array}$ & $\begin{array}{l}\text { 4.1 Universal Design for Learning } \\
\text { 4.2 Participation }\end{array}$ \\
\hline $\begin{array}{l}\text { 5. Staff Development and } \\
\text { Training }\end{array}$ & $\begin{array}{l}\text { 5.1 Reflective Practice } \\
\text { 5.2 Pre-service and in-service training as } \\
\text { teaching teams }\end{array}$ \\
\hline
\end{tabular}

\section{Diversity in the Classroom}

Diversity of the learner group was frequently noted. "What is a 'typical' classroom today (Focus group 4)?" Teachers and LSAs take on their respective roles in the knowledge that every class includes learners with different abilities and characteristics. Some students struggle, some students race ahead, some take learning in their stride, and all have different life experiences, personal learning preferences and their own different interests. "When we go round and monitor it is really difficult, when some students are way ahead and they finish, and the others have not even got out their file yet or opened their book on the right page" (Focus Group 2).

Promoting the principle that all students are equal and avoiding selection whilst respecting the natural variability in children and students, the teaching teams are responsible for delivering the mainstream National Minimum curriculum to a class of 26 students with a vast range of abilities, twenty-three non-disabled learners and three disabled learners with support entitlements. "Size, I mean classes should be more reachable" (Focus Group 3).

The majority of teaching teams within the four focus groups tended to put smaller class size at the top of their wish list: "Fewer students in a class; even 25 is too many sometimes. It depends on the class" (Focus Group 2). Interestingly, it was not the disabled learners who were considered as the 'problem', but the class size and the range of abilities within the class. "I have brilliant students who get 90 and 95 and I am speaking about physics and then we have students who get hardly 10 , and that is an enormous challenge. So what we are saying is, it is the mainstream subjects sometimes that are causing the problem, rather than inclusion itself" (Focus Group 1). In Focus group 1 the participants suggested 
that they would like to adopt different pedagogical strategies within the core lessons.

\section{Teaching Teams}

Teaching teams are synonymous with this school and are very much a part of the practice and learning support provision of the whole school. The general feeling from the participants of all four focus groups was that establishing the teaching teams has resulted in more students being reached on an individual level. Also, having the roles of the teacher and class/subject LSA clearly defined and understood by everyone is seen as important to both the teachers and the LSAs: "Having clearly defined roles helps prevent the misinterpretation of roles" (Focus group 4). Having knowledge of the LSA's role supports effective and inclusive practice and all the students gain from the LSA's presence in class. "... we can get closer to all the children, all the class, we both go around checking and helping the students" (Focus group 4).

\section{Support Structures}

In this school, support given by the LSA is differentiated at different school levels. Support is seen as being the right fit for the student when he can work alongside his peers as part of the class. "He followed the lesson, participated by answering questions, stayed quiet, but wanted to have something to do during the instruction; it was perfect" (Focus Group 3). Participants felt that the continuity of LSA support is important both for the students and for the teaching team. "It is important for the LSA to be continually available so we keep a constant situation in every lesson" (Focus Group 3). This ties in with the support the teachers feel they need from the LSA in order to reach the whole class. In Focus Group 1 teachers were upset with LSAs' lack of consistency with being present for lessons. "5 Green there were students that needed the support of an LSA, but there were no LSAs" (Focus Group 1). In Focus Group 4 it was noted that LSAs in class encourage student participation: "the LSAs' support enhances their participation" (Focus Group 4). The LSAs are also supportive during group work (Focus Group 1).

Instructional support is led by the class/subject teacher and supported by the LSA. Throughout the primary school and Forms 1 and 2 in the secondary school, all support is given in class by the teaching teams. It is interesting to note that creating independent learning opportunities to give the disabled learner autonomy and reduce dependency and labeling is seen as very important. "This can be achieved only if the teacher, along with the LSAs, truly envisage an inclusive classroom and makes sure that the LSA is not all the time next to the disabled student" (Focus Group 4). The English subject LSA also speaks about the need to empower disabled learners by getting the support levels right. "We are sometimes giving too much help, and as a result we don't help the students become independent. I believe that more tangible help in class to help access the curriculum is sometimes better" (Focus Group 4). 
In the higher Forms, from Form 3, there is flexibility and individual support is given in the form of pre and post tasks out of class. There was concern in Focus Group 1 that providing disabled learners with one-to-one instruction or a different programme, results in leaving classes without LSA support.

The participants in the focus groups showed both knowledge and an understanding of the purpose behind curricular modifications. In Focus groups 1,2 and 3 the participants spoke about adapted notes. Adapted notes were seen as helping a number of students especially with revision; the structure of the notes helps in memorisation (Focus Groups 1, 2, $3 \& 4$ ).

One of the biggest resources the school has in order to support the disabled learner are non-disabled peers, and gains are seen for both; "... students are willing to help out. Over a period of time students show an improvement in their interactive styles towards the disabled student" (Focus Group 4).

The use of strategies such as peer tutoring, co-operative group learning and team projects, benefit all students and prevents social isolation. "...disabled learners are shunned by their peers" (Focus Group 4). "We make sure that the boys are working well, and not fighting or arguing. We do our best to involve all students during group work. Students may contribute verbally through discussion, creatively by producing a drawing or by acting" (Focus Group 4). Peer tutoring working in pairs is used successfully. "It comes naturally within our system. Finding someone with whom they can stay and work with is the key" (Focus Group 1).

\section{Pedagogy and Positive Practice}

Schools that are best for all non-disabled students are also best for disabled students (Focus Groups 1, 2, 3 \& 4). "Academically we do check that decisions taken are put into practice and not left on paper" (Focus Group 4). All students are members of a class, year or form irrespective of ability or impairment (Focus Groups 1, 2, 3, \& 4). "As for the student, through experience, I have observed that each child likes to belong. Therefore, participation from the child's end is usually very positive" (Focus Group 4).

All the participants were knowledgeable of pedagogical approaches and the principles of Universal Design for Learning (UDL) (Rose, Meyer, \& Hitchcock, 2005), together with its implementation at the multiple means of representation stage. " ...basically, we use different strategies like the use of visuals, Power Points, project work, videos computer programmes, technology, games, drama and music" (Focus Group 1, 2, 3, \& 4 ). Teachers and LSAs in all four focus groups found scaffolding questions and lessons provided them with a means of engaging all learners in their classrooms.

Student engagement both in school activities and in class is greatly influenced by the schools and adults' expectations. "All teaching teams try and engage all the students in everything; this is a priority" (Focus Group 4). A participant in the same Focus Group "the LSA's support also enhances their participation" (Focus Group 4). 


\section{Staff Development and Training}

The participants viewed professional development in a broader context than inclusion. "...but staff development is not just about inclusion" (Focus Group 2). Another participant again mentions a broader context. "Different types of seminars on various topics that are related to problems encountered in the classroom, and teaching strategies, as well as other seminars, related to the formation of oneself" (Focus Group 4). Professional development in UDL strengthens the teaching teams' capacity to meet the needs of a wider range of learners in a mainstream classroom (Richmond-McGhie \& Sung, 2013). Evaluating one's own practice was seen as an important part of professional development. "We evaluate the previous week and also the adaptations that were given during the previous week. We see what worked and what didn't and try to improve on that" (Focus Group 4).

\section{Conclusion}

Now the path for the future has to be laid, and whilst there is no one formula that can be applied for successful inclusive education, there are possibilities for inclusive education processes that support disabled learners to access quality teaching and learning. The purpose of this research was to address the questions: How can teaching teams reduce the barriers to education for all learners? What practices within this model support or hinder the inclusion and education of disabled learners in a mainstream environment? This small study suggests that it is essential to coordinate LSA support in inclusive schools.

Teaching teams were created in the school studied to assist all students and reduce the labeling effect on disabled learners, whilst increasing their autonomy without reducing their entitlement for support. Through the planning of the teaching teams, every student is ensured access to the learning of the class, and therefore the teaching teams felt secure in the sense that the disabled learners were participating members of the class community. The teaching teams' collective voices yielded much broader results than expected. Whereas I expected these participants to go into more detail with regard to disabled students, they shared opinions and concerns that are much broader and central to inclusive education. Focusing on learners and avoiding a disability narrative is a direct result of this school's inclusive education journey. The teaching teams' contribution reflected commitment and vocation to the teaching profession. Furthermore, what they are proposing is more akin to universal design for learning and they gave importance to collaborative teamwork between the teacher and the LSA.

The main conclusions of the Focus Groups are that inclusive education has many facets which are challenging to implement when it comes to providing a student-centered pedagogy capable of meeting the needs of all the students in the classroom; this links to the need to consider reducing class size from 26 learners to 20 learners in every class throughout the grade levels (Biddle \& 
Berliner, 2008). This is a primary implication for practice and should be seen as a top priority for the policy makers.

Within the practice of inclusive education there is a disconnection between the need to respond to the different ranges of learning styles of the students within the classroom and the one size fits all curriculums. UDL was noted as a positive teaching strategy to address different learning styles therefore encouraging all the students to be learners.

Teachers and LSAs were viewed as professional teams and this was seen to be crucial, as key to addressing the individual needs of all the students in the classroom, hence the need for continuous professional development. Further, the provision of extensive and improved opportunities for training pre-service and in-service training as teaching teams should be seen as another priority for policy makers. To work in a team is key to the inclusion of the disabled learner together with conveying high expectation and providing intellectual challenge. Here the primary implication for practice would be carefully planned processes that are well supported together with flexible allocation of resources based on the needs of each class and teaching team. The supporting data from this case study indicates that while the teaching teams feel positive about their practice regarding shared decision-making, they want more time for collaboration and sharing of ideas.

At present, there is no international consensus about the extent to which LSAs should be utilised, circumstances that warrant their involvement, the duties they should appropriately perform, or what constitutes adequate training and supervision. Since most countries are still quite far from equitably including disabled students in mainstream classes, the opportunity is ripe for national, and international, dialogue on this issue. This school has altered the practice of support available for disabled students across the island. This research introduces the struggle for inclusive education from a different perspective, as a platform for further development within the practice of inclusive education.

\section{Acknowledgements}

I would like to take this opportunity to thank the teaching teams, for their support, co-operation and participation in this study.

\section{References}

Agius Ferrante, C., \& Falzon, R. (2011). Teacher-facilitator teams - a different experience. Unpublished research Paper presented at Antalya.

Agius Ferrante, C. (2008). Teaching teams at Stella Maris College Teacher -facilitator teams - An insight into two experiences. Journal of the European Teacher Education Network, 4, 75-87.

Agius Ferrante, C. (2012). A Case study of inclusion and diversity: a whole school approach using the social model of disability. $\mathrm{PhD}$ thesis. Northumbria University.

Batstone, D., Waghorn, J., \& Tobias, C. (2016). Obtaining rich data gives the best 
outcome for service users. Nursing times, 112(16), 11.

Barbour, R. (2014). Introducing qualitative research: a student's guide. London: Sage.

Bassey, M. (1995). Creating education through research: a global perspective of education research for the 21st century. Newark:Kirklington Moor Press in conjuction with BERA.

Bernacchio, C., \& Mullen, M. (2007). Universal design for learning. Psychiatric Rehabilitation Journal, 31(2), 167-169.

Biddle, B.J., \& Berliner, D.C. (2008). Small class size and its effects, schools and society. A Sociological Approach to Education, 3, 86-95.

Blatchford, P., Russell, A., \& Webster, R. (2012). Reassessing the impact of teaching assistants: How research challenges practice and policy. Oxon, UK: Routledge.

Dunst, C.J. (2003). Rethimnking early intervention. In M.A. Feldman (Ed.), Early intervention - The essential readings (pp. 262-281). London: Blackwell Publishing.

Goodley, D. (2010). Disability studies. An interdisciplinary introduction. London: Sage.

Hennik, M., Hutter, I., \& Bailey, A. (2011). Qualitative research methods. London: Sage.

Husserl, E. (1970). Logical investigations. New York: Humanities Press.

Lindqvist, G.C., Nilholm, L. Almqvist, \& Westo, G. M. (2011). Different agendas? The views of different occupational groups on special needs education. European Journal of Special Education, 26(2), 147-157.

Luck, L., Jackson, D., \& Usher, K. (2006). Case study: A bridge across the paradigms. Nursing Inquiry, 13(2).

Mayoh, J., \& Onwuegbuzie, A.J. (2013). Toward a conceptualisation of mixed methods; phenomenological research. Journal of Mixed Methods Research, 9(1), 91-107

O'brien, T., \& Garner, P. (Eds.) (2001). Untold stories: learning support assistants and their work. Stoke on Trent: Trentham Books.

Oliver, M. (1990). The politics of disablement. London: Macmillan Education.

Oliver, M. (1996). Understanding disability, from theory to practice. The Journal of Sociology \& Social Welfare, 23(3), Article 24.

Pijl, S.J. (2010). Preparing teachers for inclusive education; Some reflections from the Netherlands. Journal of Research in Special Educational Needs, 10(1), 197-201.

Richmond-McGhie, D., \& Sung, A.N. (2013). Applying universal design for learning to instructional lesson planning. International Journal of Whole Schooling, 9(1), 43-59.

Rose, D.H., Meyer, A., \& Hitchcock, C. (2005). The universally designed classroom: accessible curriculum and digital technologies. Boston, MA: Harvard Education Press.

Salend, S.J. (2008). Creating inclusive classrooms: Effective and reflective purposes ( $6^{\text {th }}$ ed.). UpperSaddle River, NJ, Ohio: Pearson Merrill/Prentice Hall.

Titchkosky, T. (2003). Disability, self, and society, Toronto: University of Toronto Press.

UNESCO (1994). The Salamanca statement and framework for action on special needs education.

Webster, R., Blachford, P., Bassett, P., Martin, C., \& Russell, A. (2011). The wider pedagogical role of teaching assistants. School Leadership and Management, 31, 3-20.

Yin, R. (2014). Case study research: design and methods, $5^{\text {th }}$ ed. London: Sage. 
